\title{
Flunarizine as a Supplementary Medication in Refractory Childhood Epilepsy: A Double-Blind Crossover Study
}

\author{
D. Keene, S. Whiting, P. Humphreys and P. Jacob
}

\begin{abstract}
We report a double blinded cross-over study involving Flunarizine versus placebo in the treatment of refractory childhood epilepsy. The patients studied were between the ages of 2 and 18; and were having more than 4 seizures per month not responsive to regular anticonvulsant medications. Of the 34 patients treated, 8 had a $50 \%$ decrease in their seizures during the placebo phase, 5 had a $50 \%$ decrease during the Flunarizine phase, and 1 patient had a $50 \%$ increase in seizures while taking Flunarizine. The remaining 25 patients showed no change in seizure activity in either phase. Patients having partial seizures with secondary generalization tended to do better on Flunarizine than those with other seizure types. Monitoring serum Flunarizine levels showed no significant difference between patients having improved seizure control and those who were unimproved. No significant side effects were noted with this medication, nor were any significant drug interactions noted.
\end{abstract}

RÉSUMÉ: La flunarizine comme médication adjuvante dans l'épilepsie réfractaire de l'enfance: un essai à double insu avec permutation Nous rapportons une étude à double insu avec permutation de la Flunarizine versus un placebo dans le traitement de l'épilepsie réfractaire de l'enfance. Les patients étudiés étaient âgés de 2 à 18 ans et présentaient plus de 4 crises par mois ne répondant pas à la médication anticonvulsivante usuelle. Parmi les 34 patients traités, 8 ont vu leurs crises diminuer de $50 \%$ pendant la phase placebo, 5 ont eu une diminution de $50 \%$ des crises sous Flunarizine et 1 patient a eu une augmentation de $50 \%$ des crises sous Flunarizine. Les 25 autres patients n'ont manifesté aucun changement de l'activité épileptique pendant l'une ou l'autre phase. Les patients qui présentaient des crises partielles avec généralisation secondaire semblaient mieux se porter sous Flunarizine que ceux qui présentaient d'autres sortes de crises. La surveillance des taux sanguins de Flunarizine n'a pas montré de différence significative entre les patients qui ont éprouvé un meilleur contrôle des crises et ceux qui n'ont pas été améliorés. Aucun effet secondaire de la médication et aucune interaction médicamentause significative n'a été noté.

Can. J. Neurol. Sci. 1989; 16:191-193

It has been proposed that the inward movement of calcium into cells plays a dominant role in neuronal hyperexcitability. If these fluxes could be reduced or prevented, then the control of seizures might be improved: This hypothetical role of calcium entry blockers has lead to a search for drugs that are particularly effective as calcium channel blockers in the central nervous system. Flunarizine, a long acting difluoro derivative of cinnarizine, has been postulated to be such a drug. ${ }^{2}$ In animal models it has shown anticonvulsant affects against pentylenetetrazole, electro-shock, and allyglycerine-induced seizures as well as preventing amygdala kindling. $3,4,5$ The few reported open trials in humans have shown promise with regard to improvement in seizure control.6,7.8,9.10.11 The purpose of this paper is to present the findings of a double blind crossover study of Flunarizine versus placebo in the treatment of refractory childhood epilepsy.

\section{Methods}

Patients chosen for this study had to be aged 2 to 18 years; have four or more seizures per month which had been refractory to the appropriate anti-convulsant medications for their seizure

From the Section of Neurology, Department of Pediatrics, Children's Hospital of Eastern Ontario, Ottawa

Received March 29, 1988. Accepted in final form November 14, 1988

Reprint requests to: Daniel L. Keene, M.D., Section of Neurology, Department of Pediatrics, Children's Hospital of Eastern Ontario, Ottawa,

Ontario, Canada K1H 8L1 
types; have no major cardiovascular disorder, and have parental consent prior to entry into the study.

This study was a double-blind crossover study divided into three phases. Throughout the study the patients were taking their regular medications with the levels being maintained within the "therapeutic range." Seizure pattern and frequency were recorded. Base-line determinations included an EEG, complete blood count, differential, platelet count, serum glutamic oxaloacetic transaminase (SGOT) and serum anticonvulsant levels. At the end of the four week phase, the patients were randomly assigned to either the placebo or the Flunarizine group. The Flunarizine group was prescribed $5 \mathrm{mg}$ of the drug per day if under 20 kilogram body weight, $10 \mathrm{mg}$ if between $20-40$ kilogram body weight, and $15 \mathrm{mg}$ if over 40 kilogram body weight. The families were requested to continue a seizure diary as well as a drug toxicity questionnaire. Patients were seen in clinic at 4,8 and 12 weeks after starting on the study (placebo or drug) medication. At the end of the 12 weeks, a complete blood count, platelets, differential, SGOT serum anticonvulsant levels and EEG were repeated. The drug/placebo crossover then occurred; the patients were maintained on the other agent for another 12 weeks, with visits at 4 week intervals. At the end of the third phase the above mentioned blood work and EEG were repeated.

The study was discontinued if there was an $80 \%$ increase of the baseline of seizures, if side effects were interfering with normal functions, or if compliance proved to be a problem. Compliance was checked by counting the remaining medications at each of the visits. As well serum anticonvulsant concentrations were measured for the other anticonvulsant medications the patient was taking at the time.

For analysis, the seizures were divided into major and minor groups. The seizures were considered to be minor if there was no generalized tonic clonic component. Major seizures consisted of at least some generalized tonic clonic activity. Seizure frequency for each phase was calculated for each patient. A $50 \%$ or greater improvement of seizure frequency with Flunarizine in comparison to baseline period was considered to be a clinical success. Any patient who had to be removed from the study because of increased seizure frequency or side effects was considered a failure. The patients that withdrew from the study for other reasons, (for example, lack of compliance or transfer to another city or centre) were not included in the final analysis.

A minimum number of 20 patients was calculated to be necessary to prove significant response for the drug over natural history of the illness. This was based on the values of the Fliechman tables using a level of significance of 0.05 , power of 0.8 , expected Flunarizine success rate of $60 \%$ and an expected spontaneous seizure remission rate during time of this study estimated to be $10 \%$.

\section{RESULTS}

34 patients were entered into the study (19 males, 15 females). The mean age at time of entry into the study was $\mathbf{1 5 . 5}$ years. The mean age of onset of the seizures was 2.3 years (range 0-9 years). The mean duration of seizure history was 9.2 years (range $1-18$ years). 16 patients had partial seizures; 6 partial, secondarily generalized seizures, and 12 generalized seizures.

On initial examination of the patients on entering into the study, 24 patients were subnormal intellectually and 28 patients had major behavioural problems (aggressivity, frequent mood swings). 20 patients had normal physical examination.

The initial EEG's were normal in 2 patients, diffusely slow in 4, focally slow in 2, showed generalized epileptiform bursts in 15 , and focal epileptiform bursts in 11 .

By randomization, Flunarizine followed by placebo occurred in 18 patients and the reverse occurred in 16 patients. The clinical characteristics of the two groups were similar in all aspects mentioned above.

All patients entered into this study at its onset completed all the phases. During the study 8 patients (23\%) had a $50 \%$ decrease in their seizures during the placebo phase as compared to baseline. During the Flunarizine phase their seizure frequency returned to near baseline levels. 5 patients (15\%) had $50 \%$ decrease in seizures during the Flunarizine phase as compared to baseline. One patient (3\%) however had a $50 \%$ increase in seizures during the Flunarizine phase as compared to baseline phase. The clinical characteristics of the patients with successful outcomes on Flunarizine and the patients without successful outcome (i.e., for age of onset, duration of seizure history, age at time of study, physical examination characteristics, level of intellectual function, behaviour status or initial EEG) were similar. 4 out of 5 patients with successful outcome on Flunarizine had partial, secondary generalized seizures (i.e. $67 \%$ of all having this type of seizure). The remaining patient had generalized seizures (see Table 1). There was no difference in serum Flunarizine levels between those patients having a successful outcome and those with nonsuccessful outcome. The mean Flunarizine level for the success group was $37.5 \mathrm{mg} / \mathrm{ml}$ (range $10-87.6 \mathrm{ng} / \mathrm{ml}$ ), the nonsuccess outcome group having a mean level of $23.2 \mathrm{ng} / \mathrm{ml}$ (range 9.8 to $57.5 \mathrm{ng} / \mathrm{ml}$ ).

No significant side effects were reported in any of the patients during the time they were taking Flunarizine as compared to the placebo phase for the same patient. Changes in serum levels of other anticonvulsant medications were not seen. No changes in EEG, complete blood count, platelets, differential, SGOT levels occurred at any time during this study.

\section{Discussion}

From the data gathered in this study, for the dosage used, Flunarizine appeared to be a safe drug without major side affects. It could be used with other anticonvulsant drugs as an add-on medication without significant drug interaction occurring. Its role as an anticonvulsant medication in clinical practice remains unanswered. Initial open-ended trials showed a significant reduction in seizure frequency (i.e., greater than $50 \%$ ) in a great number of patients given the drug. Binnie et al ${ }^{7}$ showed 16 out of 47 patients had such a response; Curatolo et al ${ }^{8} 8 / 21$ patients; Overweg et al ${ }^{10} 18 / 77$ patients; and Sorel ${ }^{9} 10 / 20$

\begin{tabular}{lccc}
\hline Table 1: Various Seizure Types and Their Outcomes \\
\hline \hline Seizure types & $\begin{array}{c}\text { Total } \\
\text { Number }\end{array}$ & $\begin{array}{c}\text { Number } \\
\text { Nonresponders }\end{array}$ & $\begin{array}{c}\text { Number } \\
\text { Responders }\end{array}$ \\
\hline Partial & 16 & $16(100 \%)$ & $0(0 \%)$ \\
Partial with & 6 & $2(33 \%)$ & $4(67 \%)$ \\
generalization & 12 & $11(92 \%)$ & $1(8 \%)$ \\
Generalized only & 12 &
\end{tabular}


patients. The daily dosages of Flunarizine ranged from 10 to 25 mg per day, but serum Flunarizine levels of the responders were not reported. In the double-blind studies of this drug reported the results are not nearly as convincing. Using the same criteria for successful outcome as listed above, Overweg et al ${ }^{10}$ reported 7 out of 30 patients (23\%) had a successful outcome on Flunarizine; Froscher et al ${ }^{11}$ had 4 out of 22 patients (9\%); and Cavazzutti et al ${ }^{12}$ had 4 out of 28 patients (28\%). Daily dosage of Flunarizine in their studies was between $10-15 \mathrm{mg}$ per day. Flunarizine serum levels were not readily available in these studies for comparison between patients with successful outcome and nonresponders.

Though the responses to Flunarizine reported in the literature have been generally better than our group, the numbers are not as striking as in the open trials. Daily dosages on Flunarizine received were similar in all studies. However, like our study, the duration of time the patient was taking the medicine was short in relationship to the reportedly long half-life of the drug. This means any changes in the daily dosages would take a significant time before being reflected in the drug's steady state level. It is possible that optional drug serum and tissue concentrations had not been reached in our study. An open study with increased drug dosages and serum level correlation with seizure frequency change would be necessary to further study this possibility. It is possible that the other drugs the children were taking resulted in lower Flunarizine levels without significant changes in regular anticonvulsant drug levels being seen. Even though significant serum differences between responders and nonresponders were not seen in our study, the numbers are too small to draw definite conclusions in this regard.

From review of the type of patients studied in this and other trials, it is quite possible that patient selection played a pivotal role in determining outcome. In our study patients with partial seizures with secondary generalization tended to have better response than patients with either partial seizures or generalized seizures alone. Whether this is a bias of sampling or not cannot be answered from our study due to the small number. From reviewing the literature, it was difficult to ascertain which seizure types tended to respond to Flunarizine due to inadequate patient population definition. In order to answer this question a larger number of patients with a single seizure type would have to be studied. The phases for such a study would have to be significantly longer to account for the pharmacokinetic properties of the drug. The daily dosage of the drug might also have to be substantially increased.

\section{ACKNOWLEDGEMENTS}

We wish to acknowledge the help given by B. Cummings, Nurse in the Epilepsy Clinic of the Children's Hospital of Eastern Ontario; Helen Findlay and Janssen for their generous support.

\section{REFERENCES}

1. Meldrum B, et al. Hypoxia and neuronal hyperexcitability, a clue to mechanisms of brain protection. In: Wanquier $\mathrm{A}$, et al, eds. Protection of Tissue against Hypoxia. Amsterdam: Elsevier Biomedical Press 1984; 276.

2. Ashton D, Marrannes R, Pauwels PJ, et al. Possible mechanisms of Flunarizine's anticonvulsant activity. In: International Workshop on Flunarizine in Epilepsy. Health Science Review Beerse 1985; 45-59.

3. Ashton D, Wanquier A. Effects of some anti-epileptic neuroloptic and gabaminergic drugs on seizures induced by D.L-allylglycerine. Pharmacol Biochem Behavior 1979; 11: 221-226.

4. Ashton D, Wanquier A. Behavior analysis of effects of 15 anticonvulsants in the amygdaloid kindled rats. Psychopharmacology 1979; 65: 7-13.

5. Desmedt LK, Niemeggers, CJE, Jansseen PAJ. Anticonvulsive properties of cinnarizine and Flunarizine in rats and mice. Arnzeimittel-Forschung 1975; 25: 1408-1413.

6. Declerk AC, Wanquier A. Double-blind study of the effectiveness of Flunarizine in therapy resistant epilepsy in mentally retarded children. In: Wada JA, Penry JK, et al, eds. Advances in Epileptology. New York: Raven Press 1980; 356.

7. Binnie CD, De Beukelaar $F$, et al. Open dose ranging trial of Flunarizine as add-on therapy in epilepsy. Epilepsia 1985; 26: 424-428.

8. Curatolo P, Cusmai R, et al. Flunarizine in therapy resistant epilepsies of infancy and childhood. International Congress on Migraine and Epilepsia (abst). Rome 1986.

9. Sorel L. Flunarizine, comme medication complementaire dans les epilepsies rebelles etude ouverte. Boletin da liga Portuguesi Contra a Epilepsia (abst) 1986.

10. Overweg J, et al. Double-blind placebo-controlled trial of Flunarizine as add-on therapy in epilepsy. Epilepsia 1984: 25: 217-222.

11. Froscher W, Bulau P, Burr W, et al. Double-blind placebo controlled trial of Flunarizine in therapy resistant epileptic patients. In: International Workshop on Flunarizine in Epilepsy. Health Science Review Beerse 1985; 81 -88.

12. Cavazzutti GB, Galli V, Benatti A. Use of Flunarizine in pediatric epilepsy. International Congress on Migraine and Epilepsia (abst). Rome 1986 